\title{
РЕЧЕВАЯ РЕПРЕЗЕНТАЦИЯ КОНЦЕПТА «ЛЕКАРСТВО» В ДОКУМЕНТАХ «АПТЕКАРСКОГО ПРИКАЗА» (XVII В.)
}

\section{SPEECH REPRESENTATION OF THE DRUG CONCEPT THE DOCUMENTS OF THE PHARMACEUTICAL ORDER OF $17^{\text {TH }}$ CENTURY}

\section{O. Olekhnovich}

Summary: The article is devoted to the analysis of the'drug' concept which is one of the components in the conceptual framework of medicine. It is a dynamic entity with a set of characteristics. The method of frame modeling makes it possible to reveal its ontological specificity and to determine the mechanism of its formation in various fields of medical discourse as exemplified in the documents of the "Pharmaceutical Order» (17th century). The 'drug' concept has different characteristics: name, composition, dosage form, packaging, pharmacological properties, indications for use, method of preparation, method of administration, dosage, special instructions, condition of dispensing. They are presented in different genres of documents of the «Pharmaceutical order»: a doctor's tale, a pharmaceutical tale, an inscription, a prescription, a schedule, a catalog, an inventory, a list, a register, each of them actualizes certain characteristics of the concept.

Keywords: medicine, 'drug' concept, discourse, doctor's tale, pharmaceutical tale, prescription, schedule, catalogue, register.

\author{
Олехнович Ольга Георгиевна \\ К.филол.н., дочент, Уральский Государственный \\ Медицинский Университет (2. Екатеринбург) \\ olgaolech@yandex.ru
}

Аннотация: Статья посвящена анализу концепта «лекарство» - одного из компонентов концептосферы медицины. Это динамическое образование, обладающее комплексом характеристик. Метод фреймового моделирования дает возможность раскрыть его онтологическую специфику и определить механизм его формирования в разных сферах медицинского дискурса на примере документов «Аптекарского приказа» (XVII в.). Концепт «лекарство» имеет разные характеристики - наименование, состав, лекарственная форма, упаковка, фармакологические свойства, показания к применению, способ приготовления, способ применения, дозировка, особые указания, условие отпуска. Они представлены в разных жанрах документов «Аптекарского приказа»: докторская сказка, аптекарская сказка, рецепт, роспись, перечень, реестр, каждый из которых актуализирует те или иные характеристики концепта.

Ключевые слова: медицина, концепт «лекарство», дискурс, докторская сказка, аптекарская сказка, рецепт, роспись, перечень, реестр.
K онцепт «лекарство» представляет собой один из важных компонентов концептосферы медицины. Механизм его формирования обозначился уже в период XVII века, когда в России медицина становилась самостоятельной дисциплиной. Этому способствовало создание Аптекарского приказа - государственного учреждения, который распоряжался всем медицинским и аптечным делом. В условиях сложившейся документноприказной системы для обслуживания медицины создаются разного рода медицинские системы, медицину сопровождали документы, в которых встречаются практически все известные на тот период лекарственные средства. Лекарства не только привозят из-за границы, их создают в аптеках под руководством подготовленных иностранных специалистов.

Для анализа используются медицинские документы Аптекарского приказа, основная часть которых хранится в Российском Государственном Архиве Древних Актов (РГАДА) в г. Москве в - Фонд 143, 2724 ед. хр., 1629-1716 гг. [3]; опубликованные рукописи в «Материалах по истории медицины в России» [2] и в «Актах исторических, собранных и изданных Археографическою комиссией» [1].
Под концептом понимается «глобальная мыслительная единица, представляющая собой квант структурированного знания. Концепты - это идеальные сущности, которые формируются в сознании человека» $[6,14]$.

Имя концепта «лекарство» имеет немало синонимов «лекарственный препарат», «препарат», «лекарственное средство», «медикамент», «снадобье», «фармаконим»[9, 93]. В исследованных нами источниках «лекарство» используется в качестве основного, иногда его заменяет «состав» (Два лекарственных состава для царицы Марии Ильиничны [3, оп. 2, ед. хр. 72а]; состав от очей $[1,287])$, «запас» (Роспись аптекарским запасом [3, оп. 2, ед. хр. 368]), «зелье» [3, оп. 2, ед. хр. 363], «оптекарское лекарство» [3, оп. 2, ед. хр. 1105, л. 1].

Что касается термина «лекарство», то оно не всегда встречается в специальных словарях. Например, в Словаре фармацевтических терминов: промышленная технология лекарств. Из всех выше приведенных терминов есть толкование «лекарственного растительного сырья» (с. 34). В Энциклопедическом словаре медицинских терминов - «лекарство» см. «лекарственный пре- 
парат» > «лекарственный препарат» см. «препарат» [7, 110] > «препарат» - син. «медикамент», «препарат лекарственный» - лекарственное средство в готовом для применения виде. [7, 367]. Практически авторы словаря считают все предложенные термины синонимами. Нельзя не согласиться с мнением Перцева, который считает ошибочным объединять разные, по его мнению, понятия. Он считает, что это не совсем приемлемо, поскольку исходное сырье (лекарственная субстанция) и конечный продукт (лекарственный препарат) не могут обозначаться одним термином (лекарственное средство) [10]. Довольно авторитетный специалист в области лекарственной индустрии и Коржавых Э.А. отмечает: «До сих пор «продолжается поиск оптимальных дефиниций таких понятий, как лекарственное средство, лекарственный препарат, лекарственная форма, лекарство, лекарственное вещество». [Маслова, с. 26].

Слово «лекарство» довольно быстро закрепилось в медицинском лексиконе и относилось к любому лекарственному средству, имеющему отношение к лечению. Под концептом «лекарство» мы будем понимать любое вещество, которое направлено на лечение больного с целью его выздоровления, т.е. будем использовать его как обобщающее понятие. Тем более в период XVII века одно и то же вещество могло быть и лекарственным сырьем, и лекарственным веществом (входило в состав определенного лекарства), и само по себе могло быть лекарством. Такой широкий охват исследуемого материала дает возможность учесть все возможные корреляции при формировании концепта «лекарство».

Концепт «лекарство» - это динамическое образование, обладающее комплексом характеристик: наименование, состав, лекарственная форма, упаковка, фармакологические свойства, показания к применению, место получения, способ приготовления, способ применения, дозировка, особые указания, условие отпуска из аптеки, упаковка, хранение. Он представлен в разных жанрах документов «Аптекарского приказа»: докторская сказка, аптекарская сказка, рецепт, роспись, перечень, реестр, каждый из которых актуализирует те или иные характеристики концепта.

Наименования лекарств, в том или ином виде, присутствует во всех представленных жанрах независимо от заданного сценария. Другое дело, что они по-разному экстраполируют одно и то же наименование. По этой причине название одного и того же денотата может иметь расхождения.

\section{Номинируются лекарства по разному принципу.}

Приведем примеры основных ономасиологических моделей: номинация по симптомам болезней, часто включающие в свой состав лекарственную форму (водка апопоклектика 'относящаяся к параличу', порошок для поносу, порох от насморку, пластырь от мозолю, порох от кашлю, лекарства потовые, мазь от сверботы 'чесотки'; порохъ десентерикус 'относящийся к дизентерии', номинация по больному органу (пилюль головные, состав отъ утробы 'живота'; очное 'глазное' лекарство; номинация по особенностям приготовления (масло мушкатное перепускное или густое); по действию на организм (лекарства легкие или тяжелые) и др.

Но это не основные номинации. Большинство наименований ориентировано на состав. Отметим основные идеографические модели: название лекарственного сырья растительного происхождения (трава мелифолиум 'тысячелистника', корень чемеричной 'чемерицы черной', цвъть ловендуловъ 'цветки лаванды', кора померанцовая, сгомя кроповое 'укропа', трава 'подорожника', ягоды земленицы 'земляники'); животного происхождения (спермачет, кость оленья, глаза раковые, олений рог, черви, клюка лягушачья); минерального происхождения (магнитъ, ентарь желтой, камень самфир 'сапфир', жемчуг, камень аматитисъ 'аметист'); названия продуктов первичной обработки, номенклатура которых строится на основе слов 'масло' (масло анисовое, масло миндалное горкое); 'гумми' (гума гутъ, гума галбани); 'смола' (смола изъ святого дерева, резина шкамонии); названия фармацевтической химии (фитриолиум-мартис'железа сульфат', купорос зеленый 'железа сульфат', дух из нашатырю 'нашатырный спирт', духъ изъ соли 'хлороводородная кислота'); названия лекарственных форм (эссенция из галгану, тинктура из шафрану, пластырь милилотный ('донника'), экстракт полынный, спирт можжевеловый, сок солодкого дубца 'солодки').

Bсе названия имеют варианты практически на всех уровнях языка. Приведем лишь единичные примеры: с фонетическими вариантами (Extract[i] helleb[ori] nigr[i] > (экстракти) елеболи нигри [3, оп. 2, ед. хр. 1059, л. 1617) // экстракту элебури нигри [3, оп. 2, ед. хр. 874, л. 2] // экстрактум елебури нигли [3, оп. 2, ед. хр. 965, л. 20]; [3, оп. 2, ед. хр. 1068, л. 61], Scorzoner[ae] > скорценеры [3, оп. 2, ед. хр. 1059, л. 26-27] // скорценерлы [3, оп. 2, ед. хр. 1372, л. 527] // скорценерры [3, оп. 2, ед. хр. 1372, л. 536] // скорцинеры [3, оп. 2, ед. хр. 1059, л. 10]); с лексическими вариантамим, в основном связанными с заимствованиями из латинского языка (Syrupi cerasorum $(2,829,10)>$ Cыропу из вишен [3, оп. 2, ед. хр. 829, л. 10-10a] // (Copony) церазорум [3, оп. 2, ед. хр. 965, л. 13]; rad[icis]; Asar[i] > Корени подлеснику [3, оп. 2, ед. хр. 875, л. 7-8] и [Корень] азарум // подлъсник [3, оп. 2, ед. хр. 956, л. 26]; Syrupi Acetosae > cыропу из щавлю люцкого [3, оп. 2, ед. хр. 829, л. 10-10а] // сыропу ацетозе [3, оп. 2, ед. хр. 877, л. 10]; с морфологическими вариантами (Herb[ae] hyssop[i] > mравы ucony [3, оп. 2, ед. хр. 799, л. 1-2) // травы иссоповой $(2,965,32)$; ивґту лавендули [3, оп. 2, ед. хр. 1059, л. 222] // цвътуу лавендулового [3, оп. 
2, ед. хр. 965, л. 20]; со словообразовательными вариантами (olei Garyophylloru[m] > масла гвоздишного [3, оп. 2, ед. хр. 743, л. 9-10) // масла гвоздикова [3, оп. 1, ед. хр. 22 л. 1] // (масла) гвоздичного [3, оп. 2, ед. хр. 965, л. 9]; о[lei] Anisi > м[а]с[ла] анисного [3, оп. 2, ед. хр. 706, л. 7-8] // масла анисового [3, оп. 2, ед. хр. 744, л. 6]; с синтаксическими вариантами (Sem[inis]: papaver[eris]: > съьмя маку бъљлого [3, оп. 2, ед. хр. 965, л. 1-2] // сгомяни макового [3, оп. 2, ед. хр. 965, л. 41), Cons[ervae] cochlear[ii] > caxapy ис травы куклеарии [3, оп. 2, ед. хр. 826, л. 3-4] // сахару ис кохлеарии $[3$, оп. 2, ед. хр. 965, л. 34]; Syrupi rubi idæi $(2,1059,1)>$ сиропу измалины [3, оп. 2, ед. хр. 1059, л. 2] // > сыроnу ис соку малинового [3, оп. 2, ед. хр. 877, л. 4]).

Из медицинских документов «Аптекарского приказа» основная нагрузка ложится на росписи и рецепты, в меньшей степени это относится к «сказкам», каждый из которых актуализирует те или иные характеристики концепта. Во всех документах, так или иначе, фигурируют названия лекарств. Метод фреймового моделирования дает возможность раскрыть его онтологическую специфику и определить механизм его формирования в разных сферах медицинского дискурса на примере документов.

Наибольшее количество лекарств сосредоточено в информирующих документах - роспись (Росnись лекарств, привезенных из Гамбурга [3, оп. 1, ед. хр. 210]; (Рoспись лекарств, изготовленных докторами [3, оп. 2, ед. хр. 737]), перечень (Алфавитный перечень лекарств [3, оп. 1, ед. хр. 1]), реестр (Реестр лекарств [3, оп. 2, ед. хр. 898]). В основном названия указанных жанров функционируют как синонимы и включают перечень наименований лекарств.

Перечень наименований лекарств, представленный в документах, имеет более или менее устойчивый тезаурус и отличается расположением компонентов. Например, в Алфавитном перечне лекарств названия располагаются по алфавиту. Использование этого документа позволяют быстро найти необходимое лекарственное средство. Кроме, того, документы отличаются объемом информации - одни лексически более информативны, другие представлены скудным содержанием.

Номенклатурные образования в жанрах такого рода не несут особой функциональной нагрузки, но часто дают дополнительную информацию, расширяя информацию о лекарствах - о лекарственной форме, о количестве вещества, стоимости, условиях отпуска (бесплатно или платно), место сбора (Роспись травам, которые набраны и приисканы около села Чашниково $[1,467])$, место приготовления и т.п.

Медицинский рецепт расширяет концептуальное пространство «лекарства». Во-первых, он создается на латинском языке. Некоторые рецепты переводятся. Именно поэтому нам представляется возможность провести компаративный анализ не только названий лекарств, но и сценариев двух документов. Во-вторых, по своим коммуникативным возможностям рецепт превосходит информативные документы, поскольку синтагматическая организация текста включает не только номинативную часть, но и императивные конструкции, определяющие сюжет сценария, тем самым усиливая его прагматический потенциал.

Императивные включения предназначены не только для аптекаря (производителя лекарства), но для больного (потребителя лекарства).

Аптекаря они ориентируют на правильное приготовление лекарства, используя глаголы в повелительном наклонении - Divid(e) in 3 part(es) 'Раздели на 3 части.; Coque in aqv(a) simpl(ici). 'Вари в обычной воде.'; Misce pro linimento. 'Смешай для линимента.'; в сослагательном наклонении - Dentur incisa et contusa L(ege) a (rtis) in charta. 'Выдать изрезанные и измельченные (корни) по всем правилам в бумаге.; Dentur incisa et conquassata l(ege) a(rtis) in charta. 'Выдать изрезанное и перемешанное по всем правилам в бумаге'; Dentur ad scatulam. 'Выдать в

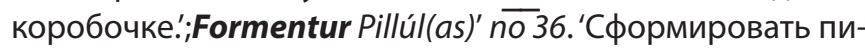
люли числом 36.'; сложные предложения с обеими формами глагола - Misce, fiant pilulae $n_{0}$ xiiij. 'Смешай, пусть получатся пилюли числом 14.'; Colatur: adde sÿrup(us): 'Пусть будет процежено, добавь сироп'; Misc(e), f(iat) pulvis subtiliss(imus). 'Смешай, пусть получится мельчайший порошок..

Нельзя не отметить использование сокращений, в их числе немало глаголов - D: $\boldsymbol{D}$ (etur) in vitro. 'Выдать в склянке.; M: Misce, divide in 5 partes. 'Смешай, раздели на 5 частей..'

Хорошо просматриваются клише, в примерах они выделены.

Императивные требования для больного предназначены на правильное употребление лекарства. 174 г. Октября въ 14 день, по росписи дохтура Самойла сделать лекарство, а въ то лекарство положить:...и то все $\underline{u}$

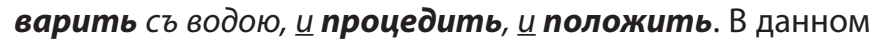
контексте союз «и» усиливает коммуникативно-прагматическую функцию императива, заостряя внимания на каждом из последовательных действий.

В определенном рецепте свои установки, это зависит не только от самого лекарства, но и от личности доктора: когда принимать и сколько - принимать по 3 лошки за час перед обгдом и перед ужином; принимать по 2 и по 3 на день до кушенья и посль кушенья по рюмкъ; и принимать в тъь поры как в мозгу болъзнь послышит и в серд- 
ие дрожание; прикладывать посльь кушенья - ложась спать; принимать по рюмкъь перед обгдом и на ночь; показания к применению - от задержания месячной крови и от того какруда гортанная идет; от болгзни - что над правым боком опухло - что яблоко; от тоски [2,797]; мазать по суставам от лому; ть лгккарства годны к ранам и к болячкам; тъ лькарства годны для поносу от многих нутренных бользней; годно от жару в ротьь полоскать $[1,483]$; как принимать - трохисси держать под языком и как станут таять и то глотать; омоча солоткой корень - сосать; парить больное мгосто как мочно терпеть, и посльь того мазать мазью и пластырь прикладывать; мазать посль паренья; намазать на плать и прикладывать на больное мгьсто; натирать больные мгста по утру и посль тово нагревать 2 плата суровых как мочно терпеть и прикладывать намазанные мъьста по переменамъ съ четверть часа; стирать с больных мгст на низ суровым платком и посль того мазать на ночь $[2,797]$. Некоторые указания связаны с особенностями больного, поэтому даются особые указания - а брюхатымъ женам сие лекарство не вредит; как пить захочет. Сюда же следует отнести последствия приема - и от того будет сон $[2,797]$.

Клише: на какое место приложить лекарство - больное мгосто; в какое время использовать - по утру, до кушенья, посль кушенья, на ночь, перед обгдом, перед ужином; как пить захочет; продолжительность использования - как мочно терпеть, съ четверть часа; показания к применению - тъ лґккарства годны для..от...

Большинство рецептов актуализируют концепт на приготовление, действий и противодействий, последствий приема лекарства иногда даже побочных действий.

В «сказках» лекарства встречаются гораздо реже, но, если мы так или иначе встречаем какие-либо названия, они дополняют представление о «лекарстве». Определение этому жанру дал Качалкин А.Н.: «Сказки - это письменные показания по определенному вопросу. Подавались они по разным поводам, когда администрации нужны были сведения по какому-либо делу, известные авторам сказок» [5, 82]. «Сказки» могут более подробно описать название (1), происхождение (2) того или иного лекарства: Дохтур Cmenaн Фунгаданов да аптекарь Яганусъ Гутменш сказали... смотря на ивът: званием по латыни эрука сильвестрис или эризимус, а по руски: дикая горчица (1). И такой де травы есть родов много: родится иная в хлъбг, а иная на мокрых и высоких мгстьъх.. трава имеет в себе в лекарства х(2) (здесь место произрастания [3, оп. 2, ед. хр. 1196].

В другой «сказке» мы узнаем о важности качества лекарства: Omпусти масл: коричного, гвоздишного, полынного да кропового. А масло отпусти самое доброе которых бы лутче не было [3, оп. 2, ед. хр. 1196]

В документах имеют место «сказки», в которых описываются эксперименты с лекарствами, например на голубях: одному дано мышьяку против двух зерен, другому голубю кости инроговы против пяти зерен; третьему голубю дано мышьяку против двух-ж зерен, кости инроговы против пяти зерен перцовых.

И которому голубю дан один мышьяк, и которому голубю дано мышьяк да после кости инроговы, и тгъ голуби померли, а которому голубю дано кости инроговы, а после того мышьяку, и тот голубь жив $[2,910]$.

«Сказка» доктора Коллинса о челебных свойствах валериановой травы и лапушника отдаленно напоминает инструкцию, которая прикладывается к использованию лекарства, она описывает названия (1), лекарственную форму, которую можно приготовить из валериановой травы (2), показаниях к применению этого лекарства (3), способах приготовления лекарств из корня лапушника (4), а также показания к применению (5) - Дохтур Самойло сказал: Трава валериана а по гречески Өу (1), пристойна: из той травы перепускать водка (2), и та водка годича от очной болезни (3); да тое ж траву за морем кладут в ушечкъ для всякого здоровья (3) и ядят от ветру (3), и у которых людей печень испортица (3)и ото всякого запору (3) и женского полу от мгосячного запору (3) принимать и от водяного запору (3). А коренье тое травы разргззать намглко сварить в ргонскомъ (4) или с соком березовым или в винг иерковном (4), и тьъм полоскать рот у которых людей в роте осыпалось (5) или иная какая бользнь или в деснах цынга (5). Да тот же корень принимать от огневой (5) и отъ морового повъттрия (5); и у раненых людей раны заживают (5); и у которых людей бывает на лице желчь (5) [3, оп. 2, ед. хр. 1057].

Таким образом, на примерах концепта «лекарство» мы увидели, что он используется в разных текстах с определенным сценарием, которые моделируют свойственные только им ситуации, и в большей или меньшей степени актуализируют разные характеристики, которыми обладает концепт.

Концепт «лекарство», представляющее концептосферу медицины, выполняет разные функции в зависимости от дискурса, в котором они разворачиваются. Метод фреймового моделирования дает возможность определить механизм формирования концепта в разных сферах коммуникации и раскрыть онтологическую специфику концепта. 


\section{ЛИТЕРАТУРА}

1. Акты исторические, собранные и изданные Археографическою комиссией. Т. 3 (1613-1645 гг.). - СПб тип. Экспедиции Государственных бумаг. - С. 474475, 479-491.

2. Материалы для истории медицины в России под ред. Мамонова Н.Е., вып. 4. - СПб., 1885. С. 1300

3. Российский Государственный Архив Древних актов (РГДДА). Фонд (Ф.) 143. Аптекарский Приказ. Опись (Оп.) 2.

4. Иллюстрированный толковый словарь фармацевтических терминов: 1. промышленная технология лекарств: руско-украинско-английский: [уч. пособ. для студ. высш. уч. завед.] / [сост.: Е.А. Рубан, В.Д. Рыбачук, С.В. Спиридонов и др.]; под ред. проф. И.М. Перцева. Харьков: НФаУ, 2016. С. 117

5. Качалкин А.Н. Жанры русского документа допетровской эпохи. Часть ІІ: Филологический метод анализа документов. Москва: Издательство Московского университета, 1988. С.120.

6. Попова 3.Д., Стернин И.А. Понятие «концепт» в лингвистических исследованиях. Воронеж. Из-во Воронежского государственного университета. 1999. С. 30

7. Энциклопедический словарь медицинских терминов: в 3-х томах. Москва: Советская энциклопедия. 1984. Т.2. С. 448

8. Люликова А.В., Селезнева Л.В., Тортунова И.А. Роль фармацевтической лексики в суггестивной коммуникации // file:///C:/Users/olekhnovich_og/ Downloads/The_Role_of_Pharmaceutical_Vocabulary_in_Suggestiv.pdf

9. Маслова И.Б., Коржавых Э.А. Терминологические исследования фармацевтического дискурса: лингводидактический обзор // Вестник Российского университета дружбы народов. Серия: Вопросы образования: языки и специальность. 2011. № 1. С. 24-30.10. // https://cyberleninka.ru/article/n/ terminologicheskie-issledovaniya-farmatsevticheskogo-diskursa-lingvodidakticheskiy-obzor

10. Перцев И.М. Размышления о фармацевтической терминологии терминологии // http://provisor.com.ua/archive/2004/N1/art_30.php

\section{○ Олехнович Ольга Георгиевна (olgaolech@yandex.ru).}

Журнал «Современная наука: актуальные проблемы теории и практики»

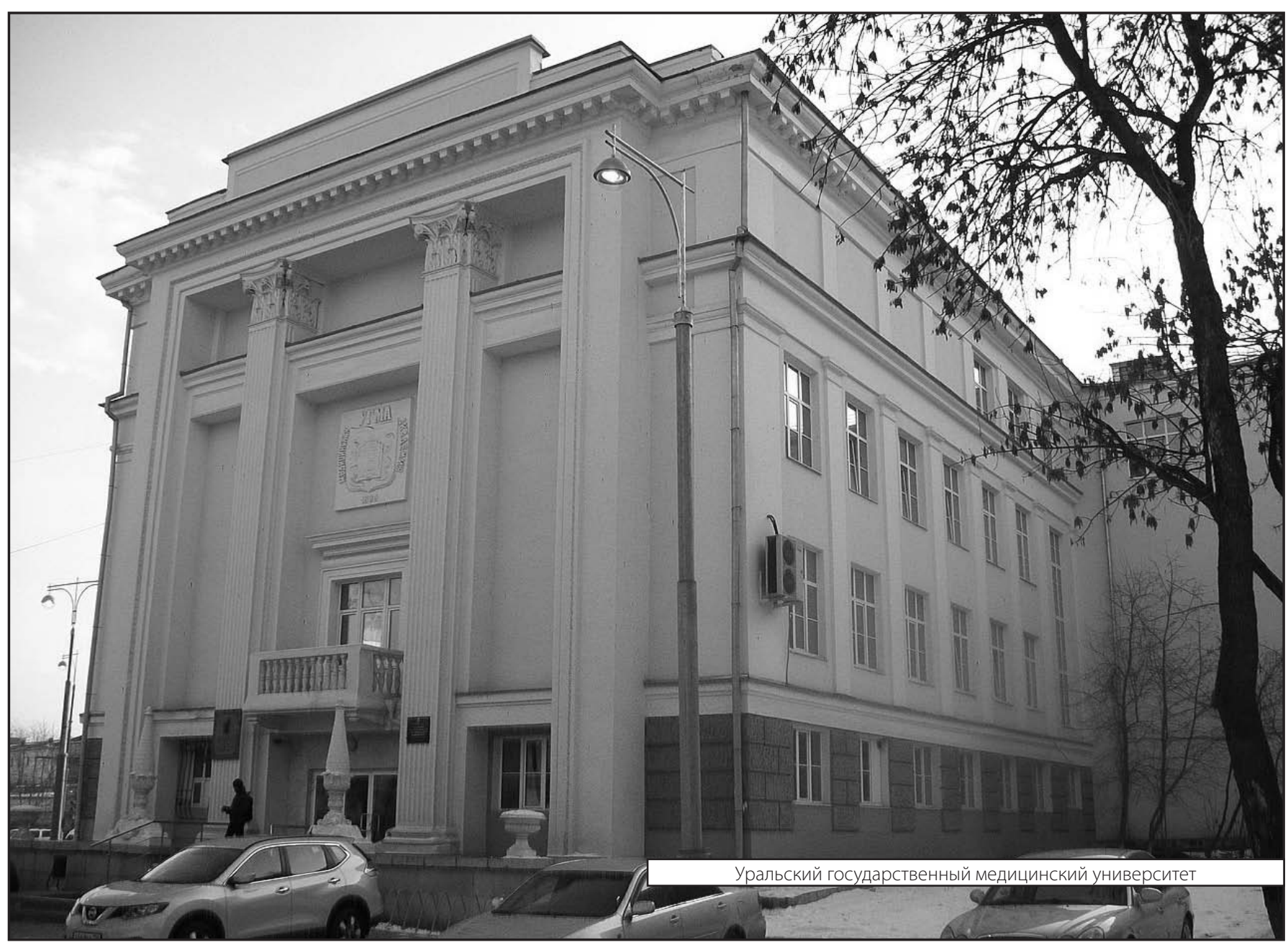

